\title{
Adjunctive enteral phenobarbital for adult status epilepticus: a brief report
}

This article was published in the following Dove Press journal:

Neuropsychiatric Disease and Treatment

25 November 2013

Number of times this article has been viewed

\author{
Somsak Tiamkao ${ }^{1,2}$ \\ Kornkanok Suttapan' \\ Sineenard Pranbul ${ }^{2,3}$ \\ Siriporn Tiamkao 2,4 \\ Kittisak Sawanyawisuth ${ }^{1,5}$ \\ Integrated Epilepsy \\ Research group ${ }^{2}$ \\ 'Department of Medicine, Faculty \\ of Medicine, Khon Kaen University, \\ Khon Kaen, Thailand; ' Integrated \\ Epilepsy Research Group, Khon Kaen \\ University, Khon Kaen, Thailand; \\ ${ }^{3}$ Nursing Division, Srinagarind \\ Hospital, Faculty of Medicine, Khon \\ Kaen University, Khon Kaen, Thailand; \\ ${ }^{4}$ Department of Pharmacy, Faculty of \\ Medicine, Khon Kaen University, Khon \\ Kaen, Thailand; ${ }^{5}$ The Research and \\ Training Center for Enhancing Quality \\ of Life of Working-Age People, Khon \\ Kaen University, Khon Kaen, Thailand
}

Correspondence: Somsak Tiamkao Department of Medicine, Faculty of Medicine, Khon Kaen University, Khon Kaen, 40002, Thailand

Tel +6643363664

Fax +6643348399

Email somtia@kku.ac.th
Background: Status epilepticus (SE) is a neurological emergency condition. Intravenous phenobarbital (PB) is recommended for refractory SE treatment. However, intravenous PB is unavailable in Thailand. Enteral PB has been shown to be effective in SE children.

Methods: In adult SE patients, the efficacy of enteral PB as an adjunctive therapy has been reported. This is a case series of adult SE patients who were treated with enteral PB at Khon Kaen University Hospital, Thailand. The clinical features and clinical outcomes are reported.

Results: There were six patients; five patients had convulsive SE, and one patient had nonconvulsive SE. All patients received PB enterally, at dosages of $900 \mathrm{mg}$ initially and repeated doses of $900 \mathrm{mg}$ as needed. This was gradually reduced to a maintenance dosage of $180 \mathrm{mg} /$ day. Three out of six patients were completely controlled, whereas the other three patients were partially controlled. Three out of six patients were seizure-free after the initial loading dose of PB. No adverse effects were found in this study.

Conclusion: In adult patients, enteral PB may be effective as an add-on for refractory SE therapy.

Keywords: clinical outcomes, refractory status epilepticus, Thailand, efficacy

\section{Introduction}

Status epilepticus (SE) is an emergency neurological condition that may lead to morbidity and mortality, especially in patients suffering over 60 minutes of SE or those developing complications from SE. The prevalence of SE is $8-41$ persons per 100,000 , with a mortality rate of $10 \%-40 \% .{ }^{1}$ SE can develop from different causes in both children and adults. Children generally develop SE from infections, whereas SE usually results from stroke and hypoxic ischemic encephalopathy in adults. ${ }^{2}$

The standard treatment of SE always begins with intravenous (IV) benzodiazepine and an IV loading of phenytoin or fosphenytoin. ${ }^{2}$ Alternatively, IV sodium valproate and IV levetiracetam are used for treatment in the early stage of SE. ${ }^{2}$ If the first- and second-line drugs cannot control the seizures, patients can be treated with IV midazolam, pentobarbital, thiopental, phenobarbital (PB), ketamine, propofol, or lacosamide to stop $\mathrm{SE}^{3}$

$\mathrm{PB}$ is a gamma-aminobutyric acid (GABA)-mediated inhibitor that has over $95 \%$ bioavailability, $48 \%-54 \%$ protein binding, a half-life of $72-144$ hours, and liver metabolism. A maintenance dose of 60-240 $\mathrm{mg}$ /day can be given in one or two doses. Its major side effects are memory disturbance, and labile behavior and emotions. However, PB has been used for over 100 years since it is effective in seizure 
control and is cost-effective, for the indications of control of partial seizure, primary generalized tonic-clonic seizure, and neonatal seizure. ${ }^{4}$

In Thailand during the fiscal year of 2010, epileptic patients aged over 18 years old were admitted to hospital 21,880 times. Of this number, SE accounted for 2,190 of the hospitalizations, with a mortality of $262(12 \%)$ of the total patients with SE. ${ }^{5}$ A number of antiepileptic drugs are used in Thailand, including phenytoin, sodium valproate, PB, topiramate, and levetiracetam. Despite the fact that PB has side effects affecting memory, behavior, and emotion, it can effectively control seizures and is available all over the country. Hence, PB is well known for the treatment of generalized tonic-clonic SE (GTCSE) seizures. Additionally, treatment with a high dose of PB infusion is accepted as efficient in SE patients. Previous studies have shown that intramuscular injection or oral PB can treat SE in children. ${ }^{6,7}$ Since 2012, only oral PB has been available in Thailand, and oral PB has been used to treat SE. Here, a case series of adjunctive enteral PB treatment, in refractory SE (RSE) in adult patients, is reported.

\section{Patients and methods}

This study is a retrospective review from the database of Srinagarind Hospital, Faculty of Medicine, Khon Kaen University (Khon Kaen, Thailand), from January 2012 to June 2012. There were six Thai SE patients who were prescribed enteral PB via a nasogastric tube (NG) for RSE, as the third-, fourth-, or fifth-order antiepileptic drug.

SE was diagnosed by the following conditions: 1) patients with over 10 minutes of continuous seizures, or 2) patients having two consecutive seizures without gaining consciousness during the pause. RSE was defined as SE not responding to the first two antiepileptic drugs and SE seizures that have persisted over 1 hour. Electroencephalography (EEG) was performed to confirm seizures and also for follow up. Patients were evaluated by brain computed tomography $(\mathrm{CT})$ or magnetic resonance imaging (MRI), cerebrospinal fluid (CSF) study, and proper investigation to determine the causes of seizures and complications.

A clinical response was based on both clinical improvement and EEG monitoring. The outcome was categorized in three groups, according to the clinical response:

- Completely controlled: patients who stopped having seizures after taking a loading dose and maintenance dose of PB, without having to reload or increase the maintenance dose
- Partially controlled: patients who still had seizures after taking a loading dose of PB and who required a reloading dose or increase of the maintenance dose to stop seizures

- Nonresponse group: patients who never stopped seizures despite taking a loading dose of PB and for whom reloading doses did not stop the seizures, and who then required another drug.

\section{Results}

\section{Clinical data}

The data were obtained from a review of the medical records of six inpatients at Srinagarind Hospital who were treated by enteral PB for RSE. There were four male and two female patients. Five patients had convulsive SE (CSE), while only one patient had nonconvulsive SE (NCSE). All patients experienced seizures approximately 5 minutes before receiving treatment. Diazepam $10 \mathrm{mg}$ was given intravenously as the first rescuer in all patients. The time between each antiepileptic drug followed the treatment guidelines for $\mathrm{SE}^{3}$ All patients were admitted to the intensive care unit and intubated with ventilation support. The average length of stay was 41.5 days. One patient died. The clinical data are reported in Table 1.

\section{Case I}

A 76-year-old man with history of diabetes and hypertension was admitted because of pneumonia and received ceftazidime and clindamycin. During admission, the patient developed acute right hemiparesis. An acute cerebellar infarction was found at the right cerebellar hemisphere, along the posterior cerebellar artery. He also developed hospitalacquired pneumonia from Acinetobacter baumannii. The patient was referred to the university hospital with Glasgow Coma Scale (GCS) score of E4VTM6 (E = eye opening; $\mathrm{V}=$ verbal response; $\mathrm{M}=$ motor response). One week later, he became comatose, had dilated pupils (4 mm, with reaction to light), with eye deviation to left side and horizontal nystagmus. The CT scan of the brain showed right cerebellar infarction with hemorrhagic transformation and also left cerebellar infarction. At day 60 of admission, he had alteration of consciousness related to hypoglycemia (plasma glucose $22 \mathrm{mg} / \mathrm{dL}$ ). He also had generalized tonic-clonic seizures for 30 minutes and was treated with $50 \%$ glucose and four times with $10 \mathrm{mg}$ IV diazepam. The seizures were persistent despite his plasma glucose returning to $128 \mathrm{mg} /$ $\mathrm{dL}$, and he did not respond to $750 \mathrm{mg}$ of IV phenytoin (two doses) or 1,200 mg of IV sodium valproate. An EEG showed 


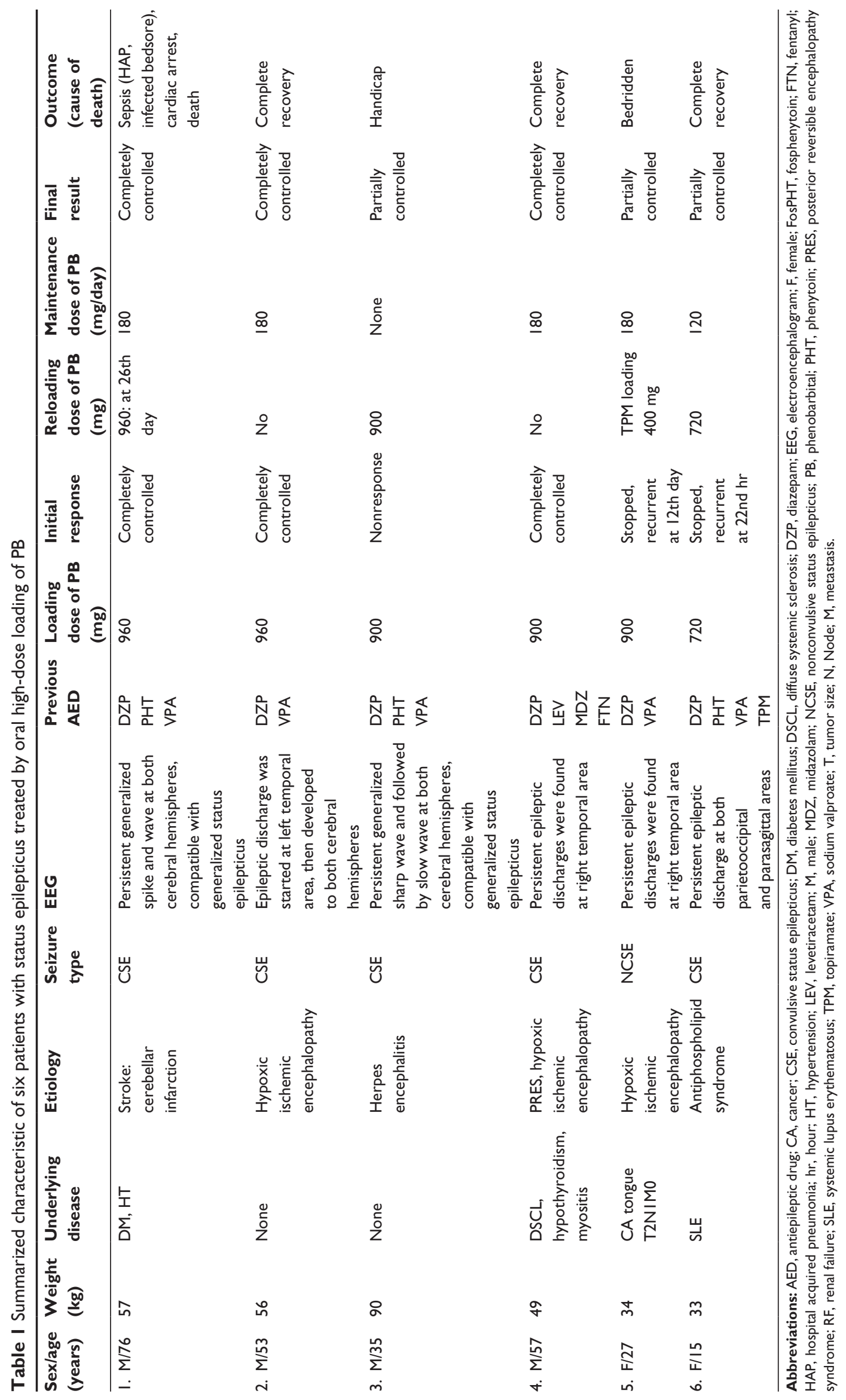


persistent generalized spikes, and waves were found in both cerebral hemispheres, compatible with CSE. He was successfully treated with $960 \mathrm{mg}$ PB via NG tube feeding. The IV phenytoin and sodium valproate were discontinued. His maintenance therapy was $180 \mathrm{mg}$ /day of PB enterally. He developed uncontrolled sepsis and a second episode of GTCSE 26 days later and was successfully treated with $960 \mathrm{mg}$ PB via NG tube feeding again. Even though the seizures were controlled, the patient had cardiac arrest and 3 hours later died, from uncontrolled sepsis.

\section{Case 2}

A 53-year-old male without prior comorbidity was admitted due to acute extensive anterior wall ST elevated myocardial infarction with cardiac arrest. He had three cardiac arrests with successful cardiopulmonary resuscitation (CPR) for 8 , 2 , and 2 minutes. The patient was comatose and developed acute kidney injury, hyperphosphatemia, mild hepatitis, and ventricular tachycardia after the CPR. He was given IV amiodarone and an intra-aortic balloon pump. The patient had a GTCSE from hypoxic ischemic encephalopathy. His SE was not controlled after treatment with IV diazepam (10 mg, four times) or IV sodium valproate $(1,200 \mathrm{mg}$, twice). An EEG showed persistent epileptic discharge, which was found starting at the left temporal area and secondary to both cerebral hemispheres. The seizures were successfully controlled with $960 \mathrm{mg} \mathrm{PB}$ via NG tube feeding. The PB level was $32.51 \mu \mathrm{g} / \mathrm{mL}(10-40 \mu \mathrm{g} / \mathrm{mL})$, and the free form of sodium valproate was $32.51 \mu \mathrm{g} / \mathrm{mL}(5-10 \mu \mathrm{g} / \mathrm{mL}) 48$ hours later. He was free of seizures with the maintenance dose of PB of $180 \mathrm{mg}$ per day and returned home completely recovered.

\section{Case 3}

A 35-year-old, previously healthy male was admitted due to a history of headaches and alteration of consciousness for 4 days. His CSF revealed 6 cells $/ \mathrm{mm}^{3}$ of red blood cells and white blood cells. An MRI brain scan was compatible with herpes encephalitis. The patient received $750 \mathrm{mg}$ IV of acyclovir every 8 hours. During hospitalization, he had GTCSE and received endotracheal intubation, 1,200 mg sodium valproate, and 1,000 $\mathrm{mg}$ IV phenytoin. The seizures were uncontrolled, and an EEG showed persistent generalized sharp waves followed by slow waves, in both cerebral hemispheres. He was given $900 \mathrm{mg}$ PB by NG tube, and the SE was partially controlled. The seizures were recurrent but successfully treated with reloading of $900 \mathrm{mg}$ of PB, IV phenytoin, and IV propofol. The PB level was
$255.55 \mu \mathrm{g} / \mathrm{mL}(10-40 \mu \mathrm{g} / \mathrm{mL})$, the free sodium valproate level was $12.21 \mu \mathrm{g} / \mathrm{mL}(50-100 \mu \mathrm{g} / \mathrm{mL})$, and the free phenytoin level was $0.75 \mu \mathrm{g} / \mathrm{mL}(10-20 \mu \mathrm{g} / \mathrm{mL})$ at day 3 after admission. A follow-up MRI showed evidence of encephalitis at the left limbic system and insular lobe of the left temporal lobe, and diffuse meningitis with evidence of basal arachnoiditis. After 23 days of admission, the patient was still comatose and was referred to a community hospital as per request from his relatives.

\section{Case 4}

A 57-year-old male patient with history of diffuse systemic sclerosis, hypothyroidism, and myositis was admitted with an acute fever with seizures for 1 day. A CT scan of the brain showed normal findings with no white blood cells in his CSF. He received piperacillin/tazobactam and 1,000 mg oral levetiracetam per day, and the seizures were controlled. During the admission, he had bronchial secretion obstruction with hypoxemia and severe metabolic acidosis, and cardiac arrest. After a successful CPR, he was comatose and developed GTCSE. An EEG showed persistent epileptic discharges in the right temporal area, compatible with SE. The seizures were uncontrolled after $5 \mathrm{mg}$ IV midazolam and an IV fentanyl infusion, at $5 \mathrm{~mL} /$ hour. Finally, $900 \mathrm{mg}$ PB, via NG tube feeding, was prescribed, with successful seizure control. He was given a maintenance dose of $180 \mathrm{mg}$ PB. The PB level was $31.61 \mu \mathrm{g} / \mathrm{mL}(10-40 \mu \mathrm{g} / \mathrm{mL})$ at 4 hours after PB administration. A repeat $\mathrm{CT}$ brain scan showed posterior reversible encephalopathy syndrome. The patient completely recovered.

\section{Case 5}

A 27-year-old female with carcinoma of the tongue stage T2N1M0, who was post-wide excision and radiotherapy, was admitted because of pneumonia. On the second day of admission, the patient had cardiac arrest from upper airway obstruction, resulting in hypoxic ischemic encephalopathy. Four days later, the patient developed tonic downward nystagmus in both eyes. An EEG revealed persistent epileptic discharge in the right temporal lobe. The diagnosis of NCSE was made, but this was not successfully controlled by $10 \mathrm{mg}$ IV diazepam or 1,200 mg of IV sodium valproate. The seizures were controlled after a loading of $900 \mathrm{mg}$ PB via NG tube feeding. The PB level at 7 hours after PB administration was $43.98 \mu \mathrm{g} / \mathrm{mL}(10-40 \mu \mathrm{g} / \mathrm{mL})$. She received $180 \mathrm{mg}$ of $\mathrm{PB}$ as a maintenance dose. She developed seizures again at day 12 after admission and was treated with oral topiramate. Her final status was bedridden. 


\section{Case 6}

A female, aged 15 years, with systemic lupus erythematosus was admitted due to seizures and diagnosed with central nervous system (CNS) vasculitis. A CT scan of the brain was normal, and the CSF had a mild elevation of protein, at $50 \mathrm{mg} / \mathrm{dL}$. She was given $1 \mathrm{gm}$ of methyl prednisolone IV for 3 days. She also had urinary tract infection and an infected bedsore. Previously, her seizures were controlled by $300 \mathrm{mg}$ of phenytoin orally. During the admission, she developed GTCSE, and her MRI of the brain showed venous infarction with hemorrhagic transformation. The SE was uncontrolled by the IV loading of $750 \mathrm{mg}$ phenytoin, $100 \mathrm{mg}$ of IV sodium valproate, and $300 \mathrm{mg}$ of oral topiramate. An EEG showed persistent epileptiform discharges at both parietooccipital and parasagittal areas. She was intubated and treated successfully with a $720 \mathrm{mg}$ PB NG tube feeding. The seizures were recurrent 22 hours later, whereupon a reloading of $720 \mathrm{mg}$ of PB enterally was prescribed for eleven times, until the seizures were completely controlled both clinically and by EEG. The PB level was $86.48 \mu \mathrm{g} / \mathrm{mL}(10-40 \mu \mathrm{g} / \mathrm{mL})$. The serological tests revealed positive anti-RO, anti-RNP, and lupus anticoagulant. She was finally diagnosed as having antiphospholipid syndrome and treated with enoxaparin and dexamethasone. The patient completely recovered.

\section{Discussion}

It would appear as if this study presents new clinical data for enteral PB use in adult patients with refractory SE. The complete control rate was $50 \%$ (three out of six patients), and the other three patients were partially controlled by enteral PB.

The present standard treatment of SE relies on benzodiazepine followed by fosphenytoin, phenytoin, or sodium valproate, with a $70 \%$ seizure control rate. ${ }^{8} \mathrm{~PB}$ has been used for seizure control for quite a long time. IV PB, but not the oral form, is approved as the standard treatment for SE. 9 A very high IV dose of $\mathrm{PB}$ has been reported to be effective in refractory SE. ${ }^{10}$ A previous study from South Africa was done in 16 children with refractory SE who were treated with $\mathrm{PB}$ via NG tube. The reason for using enteral $\mathrm{PB}$ was similar to that in this study - lack of parenteral PB. The results were very impressive, with $100 \%$ seizure control and no serious side effects.

Enteral PB absorption has been found to be quick, with dispersion of the drug at $1.2 \mathrm{~L} / \mathrm{kg}$ and with interindividual variability of 53\%. ${ }^{11}$ The PB level can reach the therapeutic range in a half hour. ${ }^{12}$ Due to the high bioavailability of oral $\mathrm{PB}$, the seizure control rates in SE of the previous and in the present study were high, at $100 \%$ and $50 \%$, respectively.
Note that some factors influence oral PB absorption in the small intestine, including the dose of PB itself and some foods or medications. A higher loading dose increases absorption, resulting in faster seizure control, and chloramphenicol or sodium valproate may partially increase PB absorption in children. ${ }^{11,13}$ Rectal or intramuscular administration of $\mathrm{PB}$ has also been found to be effective. ${ }^{6}$ Other than in SE, the oral loading of PB has been shown to be effective and safe in more than $50 \%$ of children with intractable epilepsy. ${ }^{6}$

Enteral PB has been used in the treatment of SE in children. ${ }^{11}$ The clinical variables were compared with those in this study of adult patients (Table 2). The number of patients was somewhat higher in the study of children. Enteral PB seemed to be more effective in children $(100 \%$ in children vs the $50 \%$ clinical response in this study), with no reported side effects.

The limitations of this study were the small number of patients and the retrospective data collection. The exact times in minutes of seizure control in each patient were not available but were within 1 hour. PB levels were not measured in all patients, and the measurements of drug level were done at different times after the enteral PB administration via NG tube, although the PB levels seemed to be in or over the therapeutic level. Brain tumors, particularly low-grade gliomas, may cause NCSE. ${ }^{14}$ However, this brief report had no information on this aspect. The retrospective review of all of the clinical records did not describe any side effects. One would think that if there were significant side effects, these would have been noted, but the review of the records did not disclose any. This is a shortcoming of retrospective research, and we mentioned in the discussion that a prospective study with more patients needs to be done. This current study showed the potential efficacy of enteral PB treatment in adult SE patients, and further prospective studies are required. In addition, the use of barbiturates can worsen

Table 2 Comparison of the current study with a previous study

\begin{tabular}{|c|c|c|}
\hline & Current study & Wilmshurst et al" \\
\hline $\begin{array}{l}\text { Number of } \\
\text { patients }\end{array}$ & 6 & 16 \\
\hline Age & 15-76 year & 9 days to 168 months \\
\hline Seizure type & 5 CSE, I NCSE & NA \\
\hline $\begin{array}{l}\text { Phenobarbital } \\
\text { dose }\end{array}$ & $\begin{array}{l}\text { Loading dose } 900-960 \mathrm{mg} / \text { dose } \\
\text { Maintenance dose } \\
180-360 \mathrm{mg} / \text { day }\end{array}$ & $\begin{array}{l}\text { Total dose of } \\
20-80 \mathrm{mg} / \mathrm{kg}\end{array}$ \\
\hline Response & $\begin{array}{l}\text { Completely controlled } 50 \% \\
\text { Partially controlled } 50 \%\end{array}$ & $100 \%$ seizure control \\
\hline Adverse effect & No & No \\
\hline
\end{tabular}

Abbreviations: CSE, convulsive status epilepticus; NCSE, nonconvulsive status epilepticus; NA, not applicable. 
gastrointestinal dysmotility. Enteral PB therefore should be used with caution in severely ill adult patients with SE. The efficacy also may be decreased in patients with gastrointestinal dysmotility, due to poor drug absorption.

\section{Conclusion}

Enteral PB may be effective for refractory SE, as an add-on therapy in adult patients.

\section{Acknowledgment}

The authors thank Professor James A Will for his kind review of the manuscript. This study was supported by Thailand Research Fund (TRF) grants from Senior Research Scholar Grant, Thailand Research Fund grant number RTA5580004 to Wanchai Maleewong and Pewpan M. Intapan and the Higher Education Research Promotion and National Research University Project of Thailand, Office of the Higher Education Commission, Thailand through the Health Cluster (SHePGMS), Khon Kaen University.

\section{Disclosure}

The authors report no conflicts of interest in this work.

\section{References}

1. Vignatelli L, Tonon C, D'Alessandro R; Bologna Group for the Study of Status Epilepticus. Incidence and short-term prognosis of status epilepticus in adults in Bologna, Italy. Epilepsia. 2003;44(7):964-968.
2. Brophy GM, Bell R, Claassen J, et al; Neurocritical Care Society Status Epilepticus Guideline Writing Committee. Guidelines for the evaluation and management of status epilepticus. Neurocrit Care. 2012;17(1): 3-23.

3. Meierkord H, Boon P, Engelsen B, et al; European Federation of Neurological Societies. EFNS guideline on the management of status epilepticus in adults. Eur J Neurol. 2010;17(3):348-355.

4. Brodie MJ, Kwan P. Current position of phenobarbital in epilepsy and its future. Epilepsia. 2012;53 Suppl 8:S40-S46.

5. Tiamkao S. New treatment for status epilepticus. North-Eastern Thai $J$ Neuroscience. 2012;7:1-13. Thai.

6. Kikuchi K, Hamano S, Oritsu T, et al. Effectiveness and safety of nonintravenous high-dose phenobarbital therapy for intractable epilepsy during childhood. Brain Dev. 2011;33(5):379-383.

7. Sugai K. Treatment of convulsive status epilepticus in infants and young children in Japan. Acta Neurol Scand, Suppl. 2007;186:62-70.

8. Brodie MJ, Dichter MA. Antiepileptic drug. N Engl J Med. 1996; 334(3):168-175.

9. Malamiri RA, Ghaempanah M, Khosroshahi N, Nikkhah A, Bavarian B, Ashrafi MR. Efficacy and safety of intravenous sodium valproate versus phenobarbital in controlling convulsive status epilepticus and acute prolonged convulsive seizures in children: a randomised trial. Eur $J$ Paediatr Neurol. 2012;16(5):536-541.

10. Lee WK, Liu KT, Young BW. Very-high-dose phenobarbital for childhood refractory status epilepticus. Pediatr Neurol. 2006;34(1): 63-65.

11. Wilmshurst JM, van der Walt JS, Ackermann S, Karlsson MO, Blockman M. Rescue therapy with high-dose oral phenobarbitone loading for refractory status epilepticus. $J$ Paediatr Child Health. 2010;46(1-2):17-22.

12. Turhan AH, Atici A, Okuyaz C, Uysal S. Single enteral loading dose of phenobarbital for achieving its therapeutic serum levels in neonates. Croat Med J. 2010;51(3):215-218.

13. Kwan P, Brodie MJ. Phenobarbital for the treatment of epilepsy in the 21st century: a critical review. Epilepsia. 2004;45(9):1141-1149.

14. Casazza M, Gilioli I. Non-convulsive status epilepticus in brain tumors. Neurol Sci. 2011;32 Supp1 2:S237-S239.
Neuropsychiatric Disease and Treatment

\section{Publish your work in this journal}

Neuropsychiatric Disease and Treatment is an international, peerreviewed journal of clinical therapeutics and pharmacology focusing on concise rapid reporting of clinical or pre-clinical studies on a range of neuropsychiatric and neurological disorders. This journal is indexed on PubMed Central, the 'PsycINFO' database and CAS.

\section{Dovepress}

The manuscript management system is completely online and includes a very quick and fair peer-review system, which is all easy to use. Visit http://www.dovepress.com/testimonials.php to read real quotes from published authors. 